\title{
Retour sur « Le Savoir technologique de l'Orient »
}

\section{Britta Rupp-Eisenreich}

\section{OpenEdition}

\section{Journals}

Édition électronique

URL : https://journals.openedition.org/tc/5212

DOI : $10.4000 /$ tc. 5212

ISSN : 1952-420X

\section{Éditeur}

Éditions de l'EHESS

\section{Édition imprimée}

Date de publication : 30 juin 2010

Pagination : 312-314

ISSN : 0248-6016

\section{Référence électronique}

Britta Rupp-Eisenreich, « Retour sur « Le Savoir technologique de l'Orient »», Techniques \& Culture [En ligne], 54-55 | 2010, mis en ligne le 30 janvier 2013, consulté le 29 septembre 2022. URL : http:// journals.openedition.org/tc/5212 ; DOI : https://doi.org/10.4000/tc.5212 


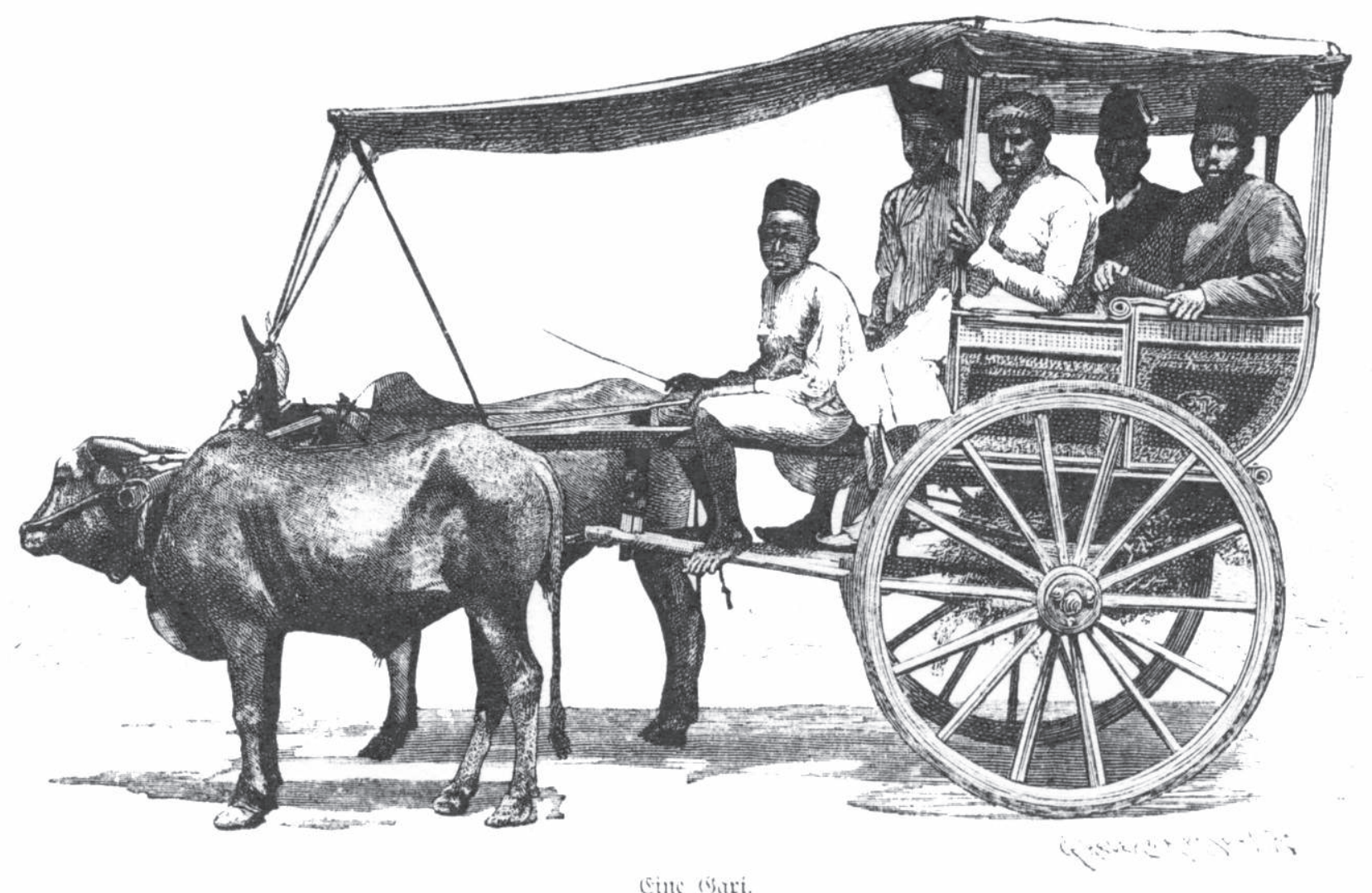

Eint GHat. 


\section{Retour sur}

\section{« Le Savoir technologique de l'Orient»}

Cette étude s'inscrit dans un ensemble de recherches qui avaient pour but de cerner les particularités historiques de l'ethnologie dans les pays de langue allemande, depuis la fin du XviII siècle et tout au long du XIXe siècle, jusqu'à l'entrée tardive de l'Allemagne dans la compétition coloniale. Ces recherches impliquaient de multiples excursions dans des domaines limitrophes tels que l'exploration et l'inventaire du monde non-occidental entrepris par des voyageurs qui ont précédé les ethnographes méthodiques. Souvent aveugles devant l'art dit «primitif » de l'Afrique et de l'Océanie, ils commençaient à entrevoir les richesses artistiques et techniques de l'Orient - en Égypte, en Assyrie, en Perse, aux Indes orientales. En témoigne l'essor de l'orientalisme, le transfert des œuvres dans les musées européens, ainsi que l'étalage qui en est fait dans les Expositions universelles, depuis l'inauguration de celles-ci à Londres, en 1851. D'emblée, elles sont consacrées aux industries de «toutes les nations » et, du moins à partir de 1867, elles comportent des sections ethnographiques vouées soit à des populations non-européennes, soit à des arts et traditions populaires rurales en Europe.

Les compétences de l'allemand Franz Reuleaux (1829-1905) en tant que technologue, spécialiste et théoricien renommé de la mécanique, l'ont amené à jouer un rôle important dans plusieurs de ces expositions. Il en a dressé l'inventaire en 1888, dans le dernier volume du «Livre des inventions » (Das Buch der Erfindungen, Gewerbe und Industrien. Rundschau auf allen Gebieten der gewerblichen Arbeit), à savoir dans la réédition, la huitième depuis 1852, des huit volumes, entièrement révisée sous sa direction, d'un ouvrage à grand tirage et très populaire, un ouvrage qui fait une large part à l'« histoire culturelle du genre humain » (Kulturgeschichte der Menschheit) en distinguant, en ce qui concerne la transmission de l'acquis, entre les sociétés fermées sur elles-mêmes, semi-ouvertes (dont l'Inde fait partie) et ouvertes. C'est en revenant de l'Exposition de Melbourne en 
1881 qu'il décida d'aller voir de près, en Inde, le maintien des pratiques artisanales dont il a pu prendre connaissance déjà auparavant, tout au long des Expositions précédentes, et notamment celle de Paris de 1878 au Trocadéro, avec sa « Section des Indes britanniques » et des principales productions artisanales des «natifs » qui, malgré l'emprise grandissante de la mécanisation moderne, se maintenaient dans les villages. Reuleaux y reprend certaines idées générales relatives au rôle de la tradition et à l'importance de la main qui, à ce stade d'évolution technique, façonne les objets. «Ladresse de l'artisan indien réside dans la tradition », dit-il. Mais déjà avant le voyage en Inde, dans son ouvrage de 1875 sur la «Cinématique théorique » ainsi que dans sa suite publiée en 1900, il fait figurer des exemples d'instruments et de techniques archaiques qui, appartenant à des degrés d'évolution préindustrielle, correspondent cependant à des catégories de mécanismes définis par sa théorie générale. Pour pouvoir concevoir une histoire évolutive des machines, y écrit-il, il faut partir des données préhistoriques et ethnographiques, de l'étude des peuples « naturels » pour connaître l'origine de l'outil, on peut avoir recours à la linguistique (Reuleaux, avant de venir en Inde, a étudié le sanskrit et il a recours aux appellations vernaculaires).

Bien qu'il soit honoré aujourd'hui à nouveau par des historiens de la mécanique rationnelle, Franz Reuleaux ne représente pas une figure majeure parmi ceux qui ont fondé et développé l'approche ethnologique. Mais par sa vision d'une saisie globale des conditions d'émergence des techniques et de l'évolution des machines vue comme une libération progressive de la main - un programme de science qui exigeait qu'au préalable soient définis les concepts fondamentaux, applicables à toute solution de perfectionnement mécanique trouvée par l'intelligence humaine dans la continuité des temps, par l'accent mis sur l'importance du geste, intégré dans sa science des mouvements, par son intérêt aussi pour le phénomène de l'invention et bien d'autres thèmes qui affleurent dans ses écrits, ceux-ci peuvent paraître en partie comme une ébauche de l'œuvre, réalisée, presqu'un siècle plus tard, par André Leroi-Gourhan, entre 1943 et 1965 (Évolution et techniques et Le Geste et la parole).

Auteur de la présente esquisse, j'ai eu le privilège, dans les années soixante du siècle passé, de suivre la formation ethnologique au Musée de l'Homme sous la direction d'André Leroi-Gourhan. Quand François Sigaut m'a invitée à participer à son séminaire à l'Ehess et à présenter quelques éléments relatifs au théoricien allemand d'une technologie générale et de les publier dans la revue Techniques $\&$ culture, ce fut pour moi une sorte de retour à l'univers intellectuel de grande envergure qu'était celui de Leroi-Gourhan, une occasion pour rendre hommage, discrètement, à mon ancien maitre, tout en enrichissant le champ de mes propres recherches. 